\title{
Evaluation of the reliability of pump combiners
}

Dominique Bisel, Olivier Gilard, Benoît Faure, Laurent Arnaud

Dominique Bisel, Olivier Gilard, Benoît Faure, Laurent Arnaud, "Evaluation of the reliability of pump combiners," Proc. SPIE 11852, International Conference on Space Optics - ICSO 2020, 118523A (11 June 2021); doi: $10.1117 / 12.2599538$

SPIE Event: International Conference on Space Optics - ICSO 2021, 2021, Online Only 


\section{International Conference on Space Optics-ICSO 2020}

Virtual Conference

30 March-2 April 2021

Edited by Bruno Cugny, Zoran Sodnik, and Nikos Karafolas
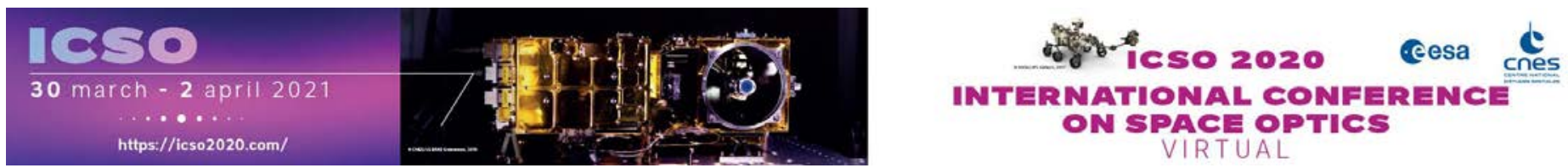

\section{Evaluation of the reliability of pump combiners}

\section{lesa icso proceedings denes}




\title{
Evaluation of the reliability of pump combiners
}

\author{
Dominique Bisel*a $^{*}$, Olivier Gilard ${ }^{\mathrm{b}}$, Benoit Faure ${ }^{\mathrm{b}}$, Arnaud Laurent ${ }^{\mathrm{a}}$ \\ a iXblue Photonics, Rue Paul Sabatier, 22300 Lannion, France \\ ${ }^{\mathrm{b}}$ CNES, 18 avenue Edouard Belin, 31401 Toulouse, France \\ *corresponding author: dominique.bisel@ixblue.com
}

\begin{abstract}
In this paper, we will describe the work carried out within the framework of the evaluation of the reliability of pump combiners under space environment. This work includes the definition of the optical and environmental specifications, the selection of the components and their evaluation.

The evaluation of these pump combiner under spatial conditions will show which reference is the most resistant to such conditions but it will also highlight what kind of environment can be destructive.
\end{abstract}

Keywords : Pump combiner, space environment

\section{INTRODUCTION}

Many space applications require, or will eventually require, the use of high power $1.5 \mu \mathrm{m}$ optical amplifiers. Among these applications, we can cite fundamental physics, TMCU, generation and distribution of intra-satellite RF frequencies, Telecoms (GEO-Ground or inter-satellite links).

The $1.5 \mu \mathrm{m}$ fiber technology is already showing a high technology readiness level (TRL) thanks to terrestrial telecoms applications. We therefore already have many technological bricks at this wavelength, with a high level of reliability and resistance to environments (qualifications such as Telcordia).

Beyond its maturity on the ground, the $1.5 \mu \mathrm{m}$ laser technology is best suited for an edge-to-ground optical link (eye safety, very high-speed access, etc.).

Work has therefore been undertaken by CNES for several years, through various R\&T, on the theme of $1.5 \mu \mathrm{m}$ amplifiers for space applications.

The first works, carried out in partnership between iXblue and CNES on this subject, focused specifically on the hardening of an Erbium-Ytterbium doped fiber, to make it less sensitive to radiative environments. This sensitivity of the fiber to radiation was until then a hard point preventing the spatialization of power amplifiers.

To achieve high output power with fiber amplifier, single mode laser diodes are not powerful enough so you must use multimode fiber coupled diodes. The optical wave at the output of these multimode diode cannot be guided in the single mode doped core of the optical fibers, double clad (DC) fibers have to be used.

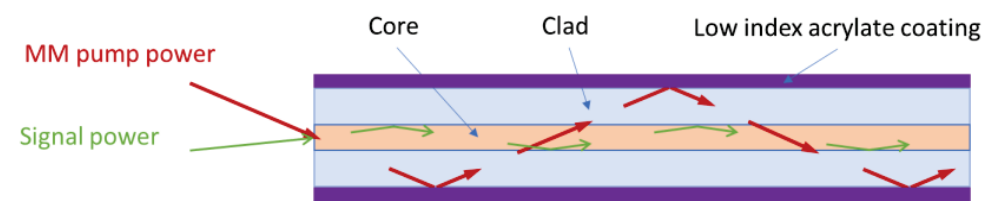

Figure 1 : Schematic description of a double clad fiber. The signal (green) is guided in the core. The pump (red) is guide in the clad 
Whatever the optical configuration of the amplifier, pump combiners must be used to inject the high-power pump power coming from the multimode diodes towards the active double clad fiber.

The low index acrylate coating does not only act as a mechanical protection, but it also allows the pump to be guided in the clad.

Depending on the wanted power of the amplifier, the pump combiner can have one or more multimode fibers.

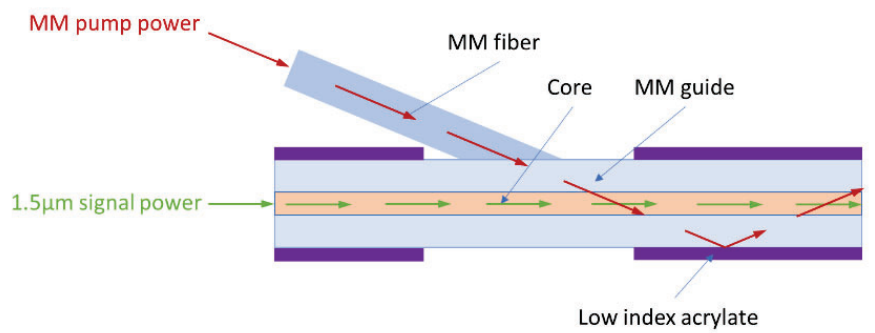

Figure 2: Example of a $(1+1)^{*} 1$ pump combiner. This combiner is made of one multimode fiber and a double-clad passive fiber with a core adapted to the active fiber and a multimode guide whose interface consists of the silica fiber and a so-called "low index" acrylate coating.

This study will focus on combiners that will be used in a 10 to 20W, C-band, Polarization Maintaining (PM) optical amplifier, that means with two 30-50W pump diodes and the iXblue Er/Yb doped, 12-130 $\mathrm{m}, \mathrm{PM}$, RadHard fiber (IXF2CF-EY-PM-12-130-RAD) as amplifying medium. These combiners are designed as: $(2+1)^{*} 1$ pump combiner. They have two MM fiber and a double clad fiber adapted to the iXblue fiber.

In this paper, we will present the results of the pump combiner reliability, but also all the previous steps as the definition of the optical and environmental specifications, the selection of optical component's manufacturers and the testing plan.

\section{EVALUATION OF THE PUMP COMBINERS RELIABILITY}

\subsection{Definition of the optical and environmental specifications}

The optical specifications of the pump combiners were defined to allow to build a 10-20W optical amplifier, in C-band, with polarization maintaining design. The insertion losses of the pump and signal power must be as low as possible to avoid over heating of the components. The core/clad diameter and NA of the output fiber were chosen to match with the $\mathrm{Er} / \mathrm{Yb}$ fiber referenced IXF-2CF-EY-PM-12-130-RAD and the multimode fibers with the most common pump diode fibers

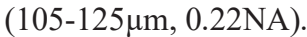

Components that must be used in spatial environment will be exposed to severe conditions of temperature, humidity, radiation, but will also undergo mechanical stresses such as shocks and vibrations.

To define the environmental specifications, we questioned potential end user of these combiners which told us which levels they have to reach for the different climatic and mechanical stress.

We ended up to the following optical and environmental specifications. 
Table 1: Optical specifications of the pump combiner

\begin{tabular}{|c|c|c|c|}
\hline & Min & Max & Units \\
\hline Signal operating wavelength & 1530 & 1570 & $\mathrm{~nm}$ \\
\hline Pump operating wavelength & 900 & 1000 & $\mathrm{~nm}$ \\
\hline Number of pump ports & \multicolumn{2}{|c|}{2} & \\
\hline Signal input fiber specifications & \multicolumn{2}{|c|}{$\begin{array}{l}\text { Passive PM single clad fiber or } \\
\text { Same as Output fiber }\end{array}$} & \\
\hline Multimode pump input fiber specifications & \multicolumn{2}{|c|}{$\begin{array}{l}\text { Passive multimode fiber } \\
105-125 \text { um } 0.22 \mathrm{NA}\end{array}$} & \\
\hline Output fiber specifications & \multicolumn{2}{|c|}{$\begin{array}{c}\text { Passive PM double clad fiber } \\
12-125 \mathrm{um} 0.17-0.46 \mathrm{NA}\end{array}$} & \\
\hline Pumping efficiency & 90 & & $\%$ \\
\hline Signal insertion loss & & 0.5 & $\mathrm{~dB}$ \\
\hline Maximum pump power per port & 50 & & $\mathrm{~W}$ \\
\hline Maximum signal in the core & 20 & & $\mathrm{~W}$ \\
\hline Maximum pump in the clad & 100 & & $\mathrm{~W}$ \\
\hline Polarization Extinction Ratio & 20 & & $\mathrm{~dB}$ \\
\hline Pump return loss & 35 & & $\mathrm{~dB}$ \\
\hline
\end{tabular}

Table 2: Environmental specifications for the pump combiner

\begin{tabular}{|c|c|c|c|c|c|c|c|}
\hline & \multicolumn{2}{|c|}{ Thermal } & \multicolumn{2}{|c|}{ Random vibrations } & \multirow[b]{2}{*}{ Shocks } & \multirow{2}{*}{$\begin{array}{c}\text { Irradiation } \\
\text { Total ionizing } \\
\text { dose (krad) }\end{array}$} & \multirow[b]{2}{*}{$\begin{array}{l}\text { Relative } \\
\text { humidity }\end{array}$} \\
\hline & $\begin{array}{l}\text { Min/Max } \\
\text { Operating } \\
\text { temperature }\end{array}$ & $\begin{array}{c}\text { Min/Max } \\
\text { Storage } \\
\text { temperature }\end{array}$ & $\begin{array}{c}\text { Perpendicular } \\
\text { to the mounting } \\
\text { plane }\end{array}$ & $\begin{array}{l}\text { Parallel to the } \\
\text { mounting plane }\end{array}$ & & & \\
\hline Max Value & $0 / 65$ & $-40 / 85$ & $24.3 / 30$ & $12.8 / 20$ & $1000 / 2000$ & 70 & 65 \\
\hline Units & ${ }^{\circ} \mathrm{C}$ & ${ }^{\circ} \mathrm{C}$ & $\mathrm{g} \mathrm{rms}$ & $\mathrm{g} \mathrm{rms}$ & $\mathrm{g}$ & $\mathrm{krad}$ & $\%$ \\
\hline
\end{tabular}

All these specifications were sent to pump combiner manufacturer to ask them for technical and commercial offers, as well as qualification results of their components.

\subsection{Component search and supplying}

A total of 14 manufacturers have been contacted, among which 9 gave us an answer with a technical and commercial offer. None of these offers totally comply with the required specifications. So, we made a selection taking account of: compliance with the specifications, qualification results, price and leadtime, production localization and feedback from previously project.

We have selected 5 references of pump combiners and have order 4 components of each to start the study. For 2 references we have re-ordered 2 components for additional results. These components didn't pass the whole testing sequency.

In order to ensure the fibers used in the combiner are hardened to radiation, iXblue supplied most of the fibers. The double clad fiber used for all the combiners is the IXF-2CF-PAS-PM-12-130-RAD and the multimode fiber is IXF-MMF-105125-0.22-RAD. 
Table 3 : Origin of passive fibers used in pump combiners of this study

\begin{tabular}{|l|c|c|}
\cline { 2 - 3 } \multicolumn{1}{c|}{} & DC fiber & MM fiber \\
\hline Supplier A & iXblue & Other \\
\hline Supplier B & iXblue & iXblue \\
\hline Supplier C & iXblue & iXblue \\
\hline Supplier D & iXblue & iXblue \\
\hline Supplier E & iXblue & Other \\
\hline
\end{tabular}

\subsection{Testing plan}

The testing plan was established to qualify the components as close as to the real use conditions. It describes the test line sequencing and the conditions of the different tests.

First step was to classify the qualification tests to have the less critical tests at the beginning of the file and to end with the riskiest tests. At first sight, the components should be less sensitive to the thermal test than to the mechanical stress.

This sequencing had to be adjusted to match with the test set ups availability or the subcontracting schedules.

Table 4: Test line sequencing

\begin{tabular}{|c|}
\hline $\begin{array}{c}\text { Initial characterization }\left(-15,25,65 \& 85^{\circ} \mathrm{C}\right) \\
\text { Damp heat }\end{array}$ \\
Intermediate characterization $\left(25^{\circ} \mathrm{C}\right)$ \\
Irradiation \\
Intermediate characterization $\left(25^{\circ} \mathrm{C}\right)$ \\
Temperature cycling \\
Intermediate characterization $\left(-15,25 \& 65^{\circ} \mathrm{C}\right)$ \\
Random vibrations \\
Intermediate characterization $\left(25^{\circ} \mathrm{C}\right)$ \\
Shocks \\
Intermediate characterization $\left(-15,25 \& 65^{\circ} \mathrm{C}\right)$ \\
Thermal vacuum \\
Intermediate characterization $\left(25^{\circ} \mathrm{C}\right)$ \\
Life test \\
Final characterization $\left(-15,25 \& 65^{\circ} \mathrm{C}\right)$ \\
Destructive analysis
\end{tabular}

Initial characterization: At reception all the components are tested. The insertion losses (IL) of the signal and pump transmission efficiency are measured at room temperature but although at $-15^{\circ} \mathrm{C}$ and $+65^{\circ} \mathrm{C}$ (and up to $85^{\circ} \mathrm{C}$ for pump transmission efficiency at mid-power). Polarization Extinction Ratio (PER) is only checked at room temperature. 


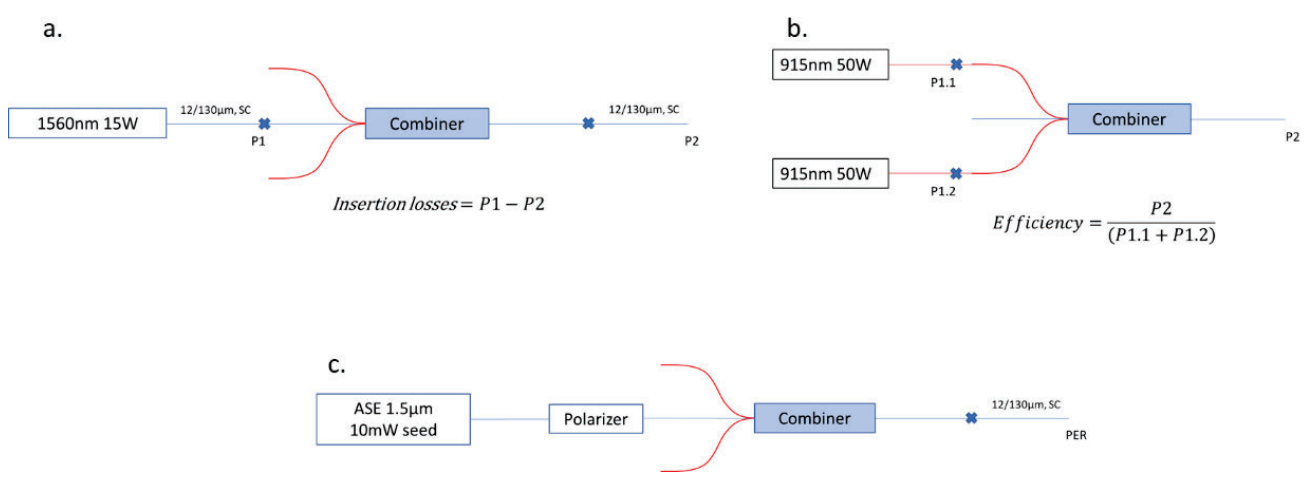

Figure 3: Description of the 3 tests made at reception and after each step of the testing plan, a. signal insertion losses (dB), $b$. pumping efficiency (\%) and c. PER (dB)

For IL and PER measurements, a short section of passive polarization maintaining $12-130 \mu \mathrm{m}$ single clad fiber is spliced at the output of the combiner to remove the part of the signal that could be guided in the clad of the pump combiner double clad output fiber.

The laser sources used to check these 3 parameters are: 15W laser source @ 1560nm for IL, 2 multimode 50W 915nm diodes for pumping efficiency and a polarized $10 \mathrm{~mW} \mathrm{C}$-band broadband source for PER.

All the following qualifications tests are done in passive mode, i.e. without any pump or signal power, excepted for Ageing test.

Damp heat (D.H.): Resistance of combiners to damp heat were tested by placing the components in a thermal chamber for $240 \mathrm{hrs}$ at $85^{\circ} \mathrm{C}$ and with $85 \% \mathrm{HR}$.

Irradiation: Components were irradiated with a Cobalt 60 source with a dose rate of $\sim 310 \mathrm{rad} / \mathrm{hr}$ and a total induced dose of about $73 \mathrm{krad}$. Sections of iXblue fibers used in the combiner were although irradiated to confirm their radiation hardening.

Temperature cycling: Combiners were exposed to 200 temperature cycles between $-40^{\circ} \mathrm{C}$ and $+85^{\circ} \mathrm{C}$, with a ramp up of $2{ }^{\circ} \mathrm{C} / \mathrm{min}$ and 30 minutes dwells.

Random vibrations: For this test, the components were splitted in 2 groups. Group 1 ( 2 components/reference) goes through Level 1 and Group 2 (1 component/reference excepted Supplier B) goes through Level 2

Table 5 : Description of the Random vibrations' levels for the 2 groups.

\begin{tabular}{|c|c|c|c|c|c|c|}
\hline \multirow{4}{*}{$\begin{array}{l}\text { Random vibrations perpendicular to the mounting plane } \\
\qquad \text { (Test in Z) }\end{array}$} & \multicolumn{3}{|c|}{ Level 1} & \multicolumn{3}{|c|}{ Level 2} \\
\hline & $20 \mathrm{~Hz}-100 \mathrm{~Hz}$ & 12 & $\mathrm{~dB} /$ Oct & $20 \mathrm{~Hz}-100 \mathrm{~Hz}$ & 12 & $\mathrm{~dB} / \mathrm{Oct}$ \\
\hline & $100 \mathrm{~Hz}-300 \mathrm{~Hz}$ & 1.5 & $\mathrm{~g}^{2} / \mathrm{Hz}$ & $100 \mathrm{~Hz}-300 \mathrm{~Hz}$ & 2.29 & $\mathrm{~g}^{2} / \mathrm{Hz}$ \\
\hline & $300 \mathrm{~Hz}-2000 \mathrm{~Hz}$ & -8 & $\mathrm{~dB} /$ Oct & $300 \mathrm{~Hz}-2000 \mathrm{~Hz}$ & -8 & $\mathrm{~dB} / \mathrm{Oct}$ \\
\hline gRMS level & \multicolumn{3}{|c|}{24.3 gRMS } & \multicolumn{3}{|c|}{30 gRMS } \\
\hline \multirow{3}{*}{$\begin{array}{l}\text { Random vibrations perpendicular to the mounting plane } \\
\qquad \text { (Test in } \mathrm{X} \text { or } \mathrm{Y} \text { ) }\end{array}$} & $20 \mathrm{~Hz}-100 \mathrm{~Hz}$ & 4 & $\mathrm{~dB} / \mathrm{Oct}$ & $20 \mathrm{~Hz}-100 \mathrm{~Hz}$ & 4 & $\mathrm{~dB} / \mathrm{Oct}$ \\
\hline & $100 \mathrm{~Hz}-300 \mathrm{~Hz}$ & 0.1 & $\mathrm{~g}^{2 / \mathrm{Hz}}$ & $100 \mathrm{~Hz}-300 \mathrm{~Hz}$ & 0.24 & $\mathrm{~g}^{2} / \mathrm{Hz}$ \\
\hline & $300 \mathrm{~Hz}-2000 \mathrm{~Hz}$ & -3 & $\mathrm{~dB} /$ Oct & $300 \mathrm{~Hz}-2000 \mathrm{~Hz}$ & -3 & $\mathrm{~dB} / \mathrm{Oct}$ \\
\hline gRMS level & \multicolumn{3}{|c|}{$12.83 \mathrm{gRMS}$} & \multicolumn{3}{|c|}{20 gRMS } \\
\hline
\end{tabular}


Shocks: As for the vibration test, the same 2 groups go through 2 shocks levels

Table 6: Description of the Shocks levels for the 2 groups

\begin{tabular}{|c|c|c|c|}
\cline { 2 - 4 } \multicolumn{1}{c|}{} & Frequency & Level 1 & Level 2 \\
\cline { 2 - 4 } All 3 axis & $100 \mathrm{~Hz}$ & $30 \mathrm{~g}$ & $30 \mathrm{~g}$ \\
\cline { 2 - 4 } & $500 \mathrm{~Hz}$ & $200 \mathrm{~g}$ & $200 \mathrm{~g}$ \\
\cline { 2 - 4 } & $2000 \mathrm{~Hz}$ & $1000 \mathrm{~g}$ & $2000 \mathrm{~g}$ \\
\cline { 2 - 4 } & $10000 \mathrm{~Hz}$ & $1000 \mathrm{~g}$ & $2000 \mathrm{~g}$ \\
\hline Shocks per axis & \multicolumn{3}{|c|}{3} \\
\hline Attenuation & \multicolumn{3}{|c|}{$\mathrm{D}=5 \% / \mathrm{Q}=10$} \\
\hline Resolution & \multicolumn{3}{|c|}{$1 / 12$ octave } \\
\hline $\begin{array}{c}\text { Additional } \\
\text { criteria }\end{array}$ & \multicolumn{3}{|c|}{$50 \%$ of SRS amplitude above 0 dB } \\
\hline
\end{tabular}

Thermal vacuum (Th.Vac.): The components were tested for $\sim 200 \mathrm{hrs}$ at $65^{\circ} \mathrm{C}$ and with a pression lower than $5 \mathrm{e}-5 \mathrm{hPa}$.

Aging: For the aging, the combiners were injected with $\sim 35 \mathrm{~W}$ of pump power at $915 \mathrm{~nm}$ splitted on both multimode arms for $1000 \mathrm{hrs}$. The aging begins at room temperature for $500 \mathrm{hrs}$, then the temperature is reached to $60^{\circ} \mathrm{C}$ for $250 \mathrm{hrs}$ and finally, it is reached to $70^{\circ} \mathrm{C}$ for the last $250 \mathrm{hrs}$.

Final characterization was made in the same conditions as the initial characterization.

Destructive analysis: The components are analyzed using several methods such as tomography, visual inspection after package aperture, microscopes, injection of red light, $365 \mathrm{~nm}$ fluorescence, ...

\subsection{Evaluation}

For all references, 4 components were supplied at the beginning of the study and have been characterized at reception. After the initial characterization, only 3 are going through the testing sequence. The last one is put aside as a "spare" component. It integrates the testing sequence after a failure. Due to unexpected results or to have more information 2 more components have been supplied from supplier A and B and integrated the study.

The graph below presents the behavior of each components through the test file. 


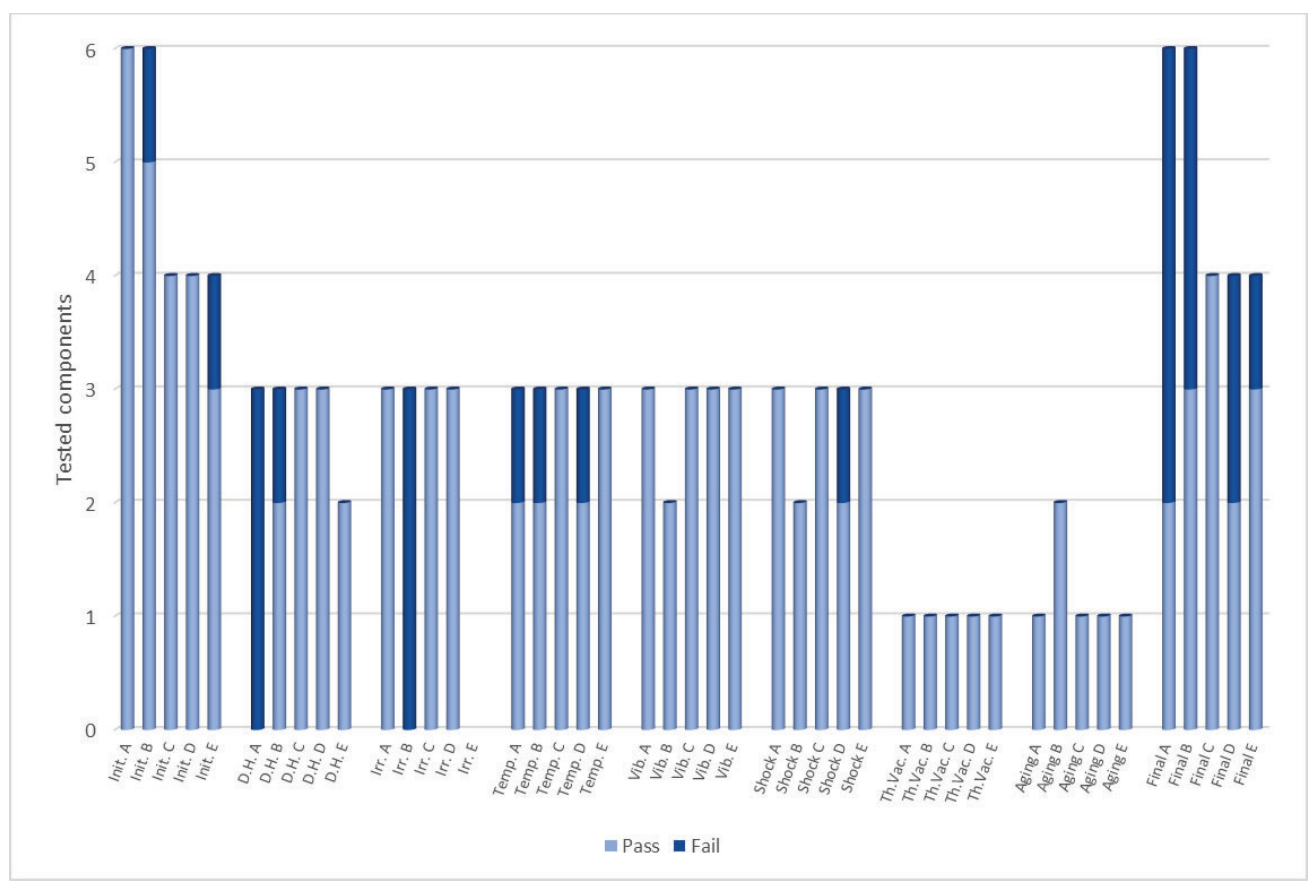

Figure 4: Results for each reference of combiner through the testing sequence

Several constatation can be done looking at Figure 4.

The $1^{\text {st }}$ one is that a characterization at reception is necessary as we can see 2 failures at this stage of the study, and for one reference (Supplier E), it is the only failure. This testing allows to identify some manufacturing issue that can occurs even with a qualified reference.

The $2^{\text {nd }}$ one is that the pump combiners seem to be very sensitive to high temperature. Indeed, the damp heat and temperature cycling tests generated many degradations. 7 components were degraded during these 2 tests which expose the combiners to a temperature up to $85^{\circ} \mathrm{C}$. It must be noted that not all the combiners were specified for such high temperature. Supplier A, for example, only guaranties a maximum storage temperature of $70^{\circ} \mathrm{C}$.

The $3^{\text {rd }}$ constatation we can do is that the components are almost insensitive to mechanicals stresses. There was only one failure (at lower level) while the levels were very high for both vibrations and shocks tests.

The $4^{\text {th }}$ constatation is that only the components from the Supplier B are sensitive to the radiations. The 3 tested components show lower transmission after this test. The power transmission gets well after the temperature cycling, which shows a healing of the combiners. This degradation is surprising as these components use iXblue fibers which are hardened to radiations.

Analysis made by the supplier show mainly a break of one or both MM fibers at the junction with the double clad fiber. It seems to be the weakness of these components.

The destructive analysis, which is still running, should give us more information about the failure mechanism due to high temperature and confirm the components are resistant to mechanical stress. 


\section{CONCLUSION}

This study brings us a lot of surprises. Contrary to what we expected, these components are much more sensitive to high temperature. On the other side, the mechanical stress levels (vibrations and shocks) that seemed very high did not cause much failure.

Based on these experimental results, we can make a classification of the combiners regarding their success through all the sequence.

Table 7 : Reliability classification of the pump combiners

\begin{tabular}{|l|c|c|c|c|c|}
\hline Supplier & A & B & C & D & E \\
\hline Final Pass/Total & $2 / 6$ & $3 / 6$ & $4 / 4$ & $2 / 4$ & $3 / 4$ \\
\hline Classification & 5 & 4 & 1 & 3 & 2 \\
\hline
\end{tabular}

Regarding to the reliability, the components we received from Supplier C are the best with no failure, followed by those from supplier E. Even if half of the components pass the tests for both Supplier B and D, Supplier D is $3^{\text {rd }}$ and Supplier B is $4^{\text {th }}$ as some components from Supplier B did not go through the entire test sequency, and the initial performances were lower. The last one is Supplier A with 4 failure out of 6 tested components.

This classification is only based on the reliability of the combiners in the previously described conditions. Depending on the project and the needed level, the classification may change. We could although taking account of the price, lead time, production lines localization.

\section{ACKNOWLEDGEMENT}

This work was funded by CNES under grant number: DSO/AQ/EC-2018.0009362 